\title{
BMJ open Improving the recruitment activity of clinicians in randomised controlled trials: a systematic review
}

\author{
Ben Fletcher, Adrian Gheorghe, David Moore, Sue Wilson, Sarah Damery
}

To cite: Fletcher B, Gheorghe A, Moore D, et al. Improving the recruitment activity of clinicians in randomised controlled trials: a systematic review. BMJ Open 2012;2: e000496. doi:10.1136/ bmjopen-2011-000496

- Prepublication history and additional appendices for this paper are available online. To view these files please visit the journal online (http:// bmjopen.bmj.com).

Received 13 October 2011 Accepted 1 December 2011

This final article is available for use under the terms of the Creative Commons Attribution Non-Commercial 2.0 Licence; see http://bmjopen.bmj.com

School of Health and Population Sciences, The University of Birmingham, Edgbaston, Birmingham, UK

Correspondence to Ben Fletcher;

fletcbrz@bham.ac.uk

\section{ABSTRACT}

Background: Poor recruitment to randomised controlled trials (RCTs) is a widespread problem. Provision of interventions aimed at supporting or incentivising clinicians may improve recruitment to RCTs.

Objectives: To quantify the effects of strategies aimed at improving the recruitment activity of clinicians in RCTs, complemented with a synthesis of qualitative evidence related to clinicians' attitudes towards recruiting to RCTs.

Data sources: A systematic review of English and non-English articles identified from: The Cochrane Library, Ovid MEDLINE, Ovid EMBASE, Ovid PsycINFO, Ebsco CINAHL, Index to Theses and Open SIGLE from 2001 to March 2011. Additional reports were identified through citation searches of included articles.

Study eligibility criteria: Quantitative studies were included if they evaluated interventions aimed at improving the recruitment activity of clinicians or compared recruitment by different groups of clinicians. Information about host trial, study design, participants, interventions, outcomes and host RCT was extracted by one researcher and checked by another. Studies that met the inclusion criteria were assessed for quality using a standardised tool, the Effective Public Health Practice Project tool. Qualitative studies were included if they investigated clinicians' attitudes to recruiting patients to RCTs. All results/findings were extracted, and content analysis was carried out. Overarching themes were abstracted, followed by a metasummary analysis. Studies that met the inclusion criteria were assessed for quality using the Critical Appraisal Skills Programme qualitative checklist.

Data extraction: Data extraction was carried out by one researcher using predefined data fields, including study quality indicators, and verified by another.

Results: Eight quantitative studies were included describing four interventions and a comparison of recruiting clinicians. One study was rated as strong, one as moderate and the remaining six as weak when assessed for quality using the Effective Public Health Practice Project tool. Effective interventions included the use of qualitative research to identify and overcome barriers to recruitment, reduction of the clinical workload associated with participation in RCTs and the provision of extra training and protected research time. Eleven qualitative studies were

\section{ARTICLE SUMMARY}

\section{Article focus}

- A systematic review to identify and synthesise evidence of evaluations of interventions aimed at improving clinician recruitment activity in RCTs, and evidence of clinicians' attitudes towards recruiting to RCTs.

\section{Key messages}

- Evidence-based recruitment interventions aimed at supporting/incentivising clinicians are necessary for future RCTs to recruit successfully. However, evidence of successful interventions is currently limited, and interventions are being used that have limited evidential grounding. The most promising intervention identified by this review was the use of qualitative methods embedded in host RCTs to define appropriate methods, targeted at clinicians, relevant to the context of the individual studies.

- The review of qualitative evidence identified a number of themes relating to clinicians' attitudes towards recruitment to RCTs. The metasummary isolated targets for future interventions aimed at improving clinicians' recruitment activity. Of particular interest were communication of trial methods, education to remove misunderstanding of trial methods and reinforcement of the potential benefits of RCTs, both for clinicians and for their patients.

identified, and eight themes were abstracted from the data: understanding of research, communication, perceived patient barriers, patient-clinician relationship, effect on patients, effect on clinical practice, individual benefits for clinicians and methods associated with successful recruitment. Metasummary analysis identified the most frequently reported subthemes to be: difficulty communicating trial methods, poor understanding of research and priority given to patient well-being. Overall, the qualitative studies were found to be of good quality when assessed using the Critical Appraisal Skills Programme checklist.

Conclusions: There were few high-quality trials that tested interventions to improve clinicians' recruitment activity in RCTs. The most promising intervention was 


\section{ARTICLE SUMMARY}

\section{Strengths and limitations of this study}

Strengths

- This review encompasses both quantitative and qualitative evidence regarding clinician involvement in recruiting to RCTs. As such, it highlights the available evidence, successful and unsuccessful interventions, areas of uncertainty and also targets for the design of future interventions.

- Qualitative data were managed and synthesised according to a set methodology and are therefore a step beyond simple narrative review. Qualitative metasummary can be the final product of a synthesis project or used as the initial step in a metasynthesis project. The purpose of qualitative metasummary was to determine how frequently each abstracted thematic finding occurred in the included studies. Qualitative metasummary is appropriate for synthesising studies that are thematic summaries or surveys of data.

\section{Limitations}

- The quality of evidence varied, and the review includes a wide range of study designs, making comparisons of interventions difficult. It is clear that RCTs of trial recruitment interventions are perceived to be difficult to carry out, so other study designs are commonly used. RCTs of recruitment interventions should be encouraged in order to increase the quality of currently available evidence.

- Methodological challenges included designing a broad search to encompass qualitative and quantitative research, quality assessment of various quantitative study designs by one set of criteria and standardising the data extraction and synthesis of qualitative evidence. There are no set guidelines regarding the synthesis of qualitative and quantitative evidence, but it is clear that for many review questions limiting the included study designs would lead to empty reviews.

the use of qualitative methods to identify and overcome barriers to clinician recruitment activity. More good quality studies of interventions are needed to add to the evidence base. The metasummary of qualitative findings identified understanding and communicating RCT methods as a key target for future interventions to improve recruitment. Reinforcement of the potential benefits, both for clinicians and for their patients, could also be a successful factor in improving recruitment. A bias was found towards investigating barriers to recruitment, so future work should also encompass a focus on successfully recruiting trials.

\section{INTRODUCTION}

When evaluating the effectiveness of healthcare interventions, randomised controlled trials (RCTs) are seen as the gold standard research design. It is important that RCTs recruit their target number of participants in order to avoid being underpowered, particularly as a lack of statistical power may lead to the reporting of clinically important effects as statistically non-significant. Statistically non-significant findings can increase the risk that potentially effective interventions may be abandoned before their true value is established or that there will be a delay in demonstrating their value while more trials are carried out. For example, Collins et $a l^{1}$ calculated that there were as many as 10000 unnecessary deaths in the USA due to delays in recruitment to a RCT of streptokinase in acute myocardial infarction. Many RCTs are abandoned or do not produce unequivocal evidence due to recruitment difficulties, which also means that the resources spent for setting up and running the RCT have not been put to their best use.

Studies that fail to recruit their target number of participants also raise ethical problems, particularly when clinicians have exposed participants to interventions with uncertain benefit and, at the end of the trial, are still unable to determine whether the intervention is clinically effective. ${ }^{2}$ There are also ethical implications associated with recruiting patients to a trial in which they invest their time, only to be told that the trial will not go ahead. There is the additional financial impact of trials that fail to recruit successfully or in a timely manner. It has been hypothesised that slow acquisition of trial evidence due to poor recruitment may have reduced investment in the conduct of RCTs by some funding agencies, which may prefer to invest in less reliable, but more rapid approaches. ${ }^{3}$ Delayed or extended trials may cost more, leading to fewer trials being carried out from the limited funds available.

There are a number of published studies that highlight how common recruitment problems are in healthcare RCTs. ${ }^{4-11}$ It is likely that $50 \%$ of RCTs fail to recruit to target and that only $50 \%$ of those that successfully recruit do so in a timely manner as shown in table 1 . The table also demonstrates the lack of any real improvement over time.

The reasons for poor or slow recruitment to RCTs can be found at various levels: the patient, the recruiting clinician, the trial centre, the trial organisation and the trial design. ${ }^{12}$ Considerable efforts have been made to understand and incentivise the participation of subjects in trials ${ }^{2}$ 3 13-16; but less has been done to investigate interventions that could improve the recruitment activity of clinicians. ${ }^{1012}$ The clinicians' role is clearly important as patients can only consider taking part in trials when asked to do so. Maintaining recruitment activity over time is also important as it has been shown that enthusiasm for recruiting subjects to RCTs can fade quickly, leading to studies that fail to recruit to target, or which suffer significant loss to follow-up due to difficulties in participant retention for the required study period. ${ }^{6}$

The objective of this systematic review was to evaluate interventions aimed at improving the activity of recruiting clinicians in RCTs and to identify possible targets for future interventions based on clinicians' attitudes to recruitment to RCTs.

\section{METHODS}

\section{Search strategy and study identification}

Systematic searches were carried out for the period January 2001 to March 2011 in the following databases: the Cochrane Library, Ovid MEDLINE, Ovid EMBASE, 
Table 1 Reports of difficulties recruiting to RCTs

\begin{tabular}{|c|c|c|}
\hline Authors & Year & Findings \\
\hline $\begin{array}{l}\text { Charleson and } \\
\text { Horwitz }^{4}\end{array}$ & 1984 & $\begin{array}{l}\text { A study of } 41 \text { trials listed with the National Institutes of Health (USA) showed that a third } \\
\text { of trials recruited }<75 \% \text { of their planned sample. }\end{array}$ \\
\hline $\begin{array}{l}\text { Easterbrook and } \\
\text { Matthews }\end{array}$ & 1992 & $\begin{array}{l}\text { A review of } 720 \text { research projects approved by the Central Oxford Research Ethics } \\
\text { Committee } 1984-1987 \text { (UK). Report states that the main reason for abandoning a study } \\
\text { was due to difficulties recruiting study participants. }\end{array}$ \\
\hline Wilson et $a f$ & 2000 & $\begin{array}{l}\text { A study of recruitment of primary care practices to an endoscopy trial. Of } 90 \text { practices } \\
\text { contacted, } 43 \text { agreed to take part, } 31 \text { recruited at least one patient and only } 23 \text { recruited } \\
\text { more than five patients. }\end{array}$ \\
\hline Foy et $a l^{p}$ & 2003 & $\begin{array}{l}\text { A study of seven primary care trials of dyspepsia management in the UK. Only one study } \\
\text { reached its recruitment target; five recruited }<50 \% \text { of target and three of these closed } \\
\text { prematurely. }\end{array}$ \\
\hline McDonald et $a \beta$ & 2006 & $\begin{array}{l}\text { A study of } 114 \text { RCTs funded by two UK funding bodies } 1994-2002 \text {. Thirty-one per cent } \\
\text { of trials achieved their original recruitment target. Fifty-three per cent were extended due } \\
\text { to recruitment problems. Early recruitment problems were identified in } 63 \% \text { of the trials. }\end{array}$ \\
\hline Bower et a $\rho$ & 2007 & $\begin{array}{l}\text { A survey of published primary care trials in the UK. Less than one third of trials recruited } \\
\text { to their original timescale. }\end{array}$ \\
\hline Raftery et $a l^{10}$ & 2008 & $\begin{array}{l}\text { Data held by the National Coordinating Centre for Health Technology Assessment (UK) } \\
\text { show that two thirds of funded trials fail to pass } 80 \% \text { of their recruitment target. }\end{array}$ \\
\hline Toerien et $a l^{11}$ & 2009 & $\begin{array}{l}\text { Review of all reports of RCTs published in July-December } 2004 \text { in six major journals. } \\
\text { Of } 133 \text { trials, } 21 \% \text { that reported sample size calculations failed to achieve adequate } \\
\text { numbers at randomisation and } 48 \% \text { at outcome assessment. }\end{array}$ \\
\hline
\end{tabular}

Ebsco CINAHL, Ovid PsycINFO, Index to Theses (UK and Ireland), Open SIGLE.

Search terms related to clinicians, recruitment and RCTs were combined to identify studies. An example search strategy is shown in online appendix 1. No methodological filters were used so that both qualitative and quantitative studies would be returned by the searches. Furthermore, filters were avoided due to the complexity of searching for trails within trials.

To determine inclusion/exclusion criteria for studies, the PICOS framework was used for quantitative studies and the SPICE framework for qualitative studies, as shown in box 1. Studies were assessed against the prespecified inclusion and exclusion criteria. Following removal of duplicate reports, a first decision on inclusion/exclusion was made based on study titles and abstracts. For those studies identified in the first stage and for studies where a definite decision could not be made based on title/abstract alone, the full paper was obtained for assessment. In the second stage, full papers were assessed against the full inclusion/exclusion criteria. Studies were also identified by performing citation searches of included studies.

Searches were carried out by one researcher $(\mathrm{BF})$, study identification by two researchers (BF and AG), and any disagreements reconciled by discussion.

\section{Quality assessment}

Quality assessment of quantitative studies was performed using the Effective Public Health Practice Project (EPHPP) quality assessment tool for quantitative studies. ${ }^{17}$ This instrument was chosen as it enables different study designs to be assessed using the same tool and was identified as one of only six judged to be suitable for systematic reviews assessing multiple study designs. ${ }^{18}$ Using the EPHPP tool, studies were assessed against six criteria: selection bias, design, confounders, blinding, data collection methods and withdrawals and dropouts.

Quality assessment of qualitative papers was carried out in accordance with the Critical Appraisal Skills Programme qualitative research appraisal tool, which covered rigour, key research methods used, credibility and relevance. $^{19}$

Quality assessment was performed by two researchers independently (BF/AG), and the results were compared for consistency. Following discussion, a consensus decision was made in the case of any disagreement.

\section{Data extraction and analysis}

For quantitative studies, data relating to study design, country, setting (ie, nature of the RCT being recruited to), population, statistical methods, description of intervention and author conclusions were extracted using a piloted data extraction form. Trials were grouped according to intervention and, if binary data were reported (ie, participants recruited/participants not recruited), then relative risk ratios were calculated. Relative risks with $95 \%$ CIs were calculated using RevMan software, where appropriate, to describe the effect of interventions.

For qualitative reports, data extraction was first carried out using the Quality Assessment and Review Instrument data extraction tool designed by the Joanna Briggs Institute for Evidence-Based Practice. This allowed broad themes to be identified in the included reports. Second, all text was extracted from sections labelled as 'results' or 'findings' in the included reports, according to the 


\section{Box 1 Study selection criteria}

PICOS Framework for quantitative studies:

Population

- Inclusion

- Clinicians recruiting to RCTS.

- Exclusion

- Subjects of RCTs.

\section{Intervention}

- Inclusion

- Any intervention aimed at improving the recruitment activity of clinicians.

- Comparison of clinicians recruiting to trials if the aim was to compare recruitment activity.

- Exclusion

- Interventions aimed at the subjects of RCTs.

\section{Comparator}

- Inclusion

- No intervention or comparison of two interventions.

- Exclusion

- Studies comparing recruitment in separate RCTs.

\section{Outcomes}

Inclusion

- Numbers/proportions of subjects recruited.

- Recruitment rates.

- Recruiting to target.

- Adherence to trial protocol regarding recruitment.

- Exclusion

- Intention to recruit.

\section{Studies}

- Inclusion

- Any study where a comparison is made between an intervention and a control group or two or more intervention group.

- Randomised controlled trials.

- Quasi-experimental studies.

Before and after studies. Interrupted time-series.

- Observational studies.

Cohort study.

Case-control study.

Case study (where there is a comparator group).

- Exclusion

- Studies with no comparator group.

- Qualitative studies.

\section{SPICE framework for qualitative studies:}

Setting

- Randomised controlled trials.

Perspective

- Clinicians directly involved in recruiting patients to RCTs.

Intervention/phenomena of interest

- Poor recruitment of RCTs.

Comparison

- None.

Evaluation

Perceived barriers and facilitator. method suggested by Thomas and Harden. ${ }^{20}$ The results were then entered into NVivo software for qualitative content analysis. Line-by-line coding of the extracted data was carried out, and codes were organised into related areas in order to construct descriptive themes. Abstracted analytical themes were then created by combining similar descriptive themes, from which frequency effect sizes could be calculated. Frequency sizes were calculated by taking the number of reports that contained an abstracted finding and dividing this number by the total number of reports. A criticism of metasummary is that it may not be appropriate to apply numbers to qualitative data. However, quantitative categorisations such as small, medium and large are often used by researchers to 'qualitize' data. ${ }^{21}$ Frequency effect sizes can be used to extract more meaning from abstracted findings. Qualitative studies 'inherently imply a frequency of occurrence of an event sufficient to constitute a pattern or theme', and metasummary can be seen as the next step in this process, as well as helping to verify the presence of themes across studies. ${ }^{22}$

Data extraction was carried out by one researcher (BF), and the results checked by a second (AG). Disagreements were resolved by discussion.

\section{RESULTS}

\section{Study selection}

The search identified 9236 abstracts, of which 296 were screened, and 38 full text papers obtained for full assessment against the inclusion/exclusion criteria. Nineteen studies were included in the review (eight quantitative and 11 qualitative) (figure 1).

\section{Study characteristics}

Of the eight included quantitative studies, three were RCTs,${ }^{23-25}$ two were observational time series, ${ }^{26} 27$ two were before and after studies ${ }^{28} 29$ and one was a case study with a comparison group. ${ }^{30}$ Two studies compared clinicians (nurses vs surgeons; community vs university medical practices).$^{23}{ }^{30}$ Two studies assessed the effect of extra involvement of trial coordinators with clinicians (extra communication; on-site initiation visits).$^{24}{ }^{25}$ One study assessed the effect of change to training and paying for protected research time on recruitment. ${ }^{29}$ Two studies from the same authors used embedded qualitative methods to identify targets for improving recruitment. ${ }^{27} 28$ One study assessed a complex multifaceted intervention. ${ }^{26}$ All but one study investigated recruitment to cancer or chronic disease trials, and the majority took place in the UK (five of eight) (table 2).

Three reports all related to the same host RCT of prostate cancer treatment. ${ }^{23} 2728$ Donovan (2002 and 2009) reported the results of using qualitative methods to develop an intervention, in both the feasibility study before the main trial and the main trial itself. Donovan (2003) compared using nurses and surgeons as recruiters in the same trial. For the purpose of this review, these three studies were assessed separately. 
Figure 1 Study selection flow diagram.

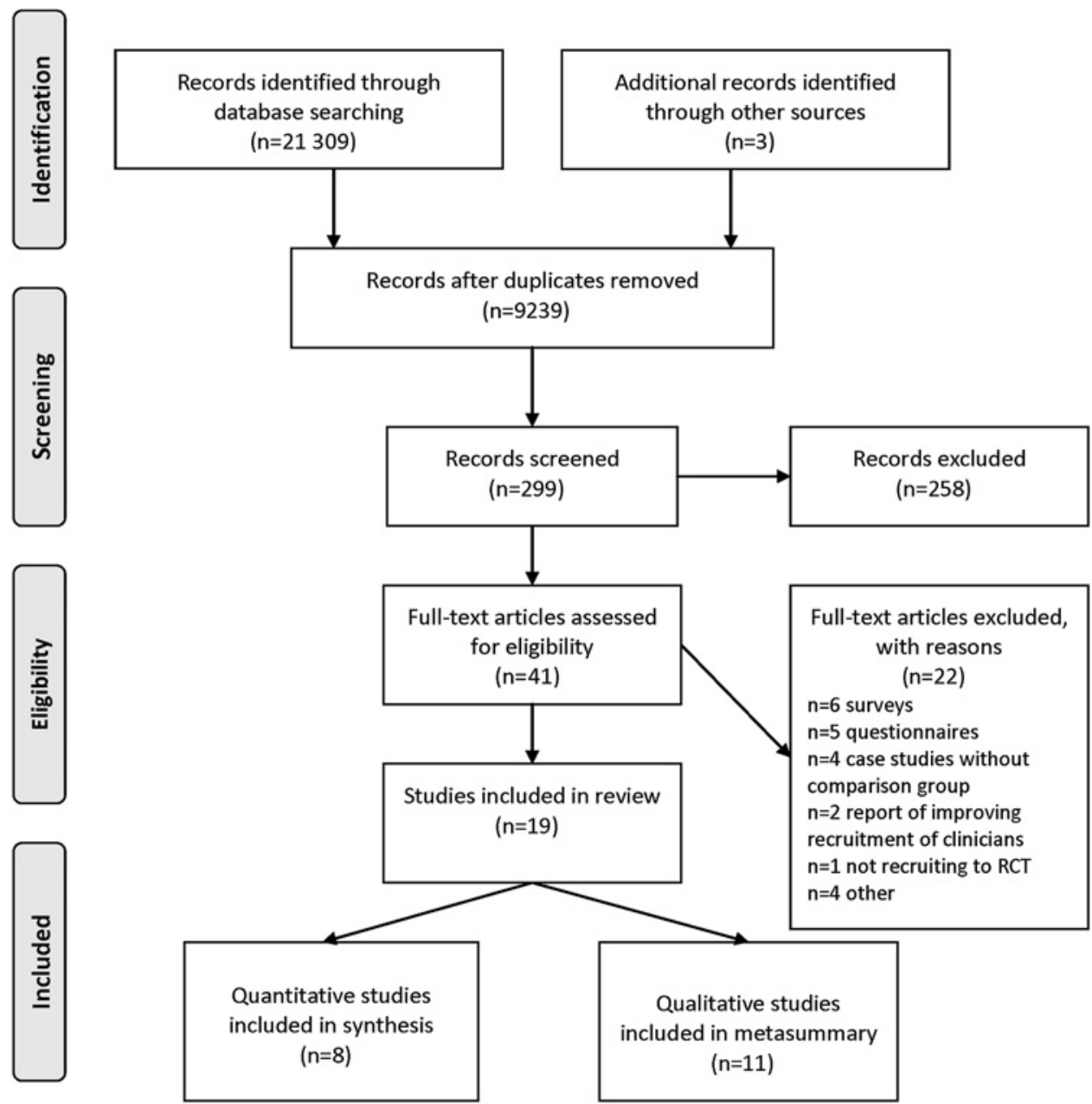

Of the 11 included qualitative studies, nine used interviews (semistructured; in-depth), ${ }^{3133} 35^{-41}$ two used focus groups ${ }^{32}{ }^{34}$ and one study also analysed trial documents. ${ }^{41}$ The methodology used was described as Grounded Theory in three studies, ${ }^{31} 3340$ while it was not stated in eight. Thematic analysis (constant comparative; framework analysis) was the most common method of data analysis (nine studies), ${ }^{31-33} 35 \quad 36 \quad 38-41$ with two studies using content analysis ${ }^{37} 41$ and one conversation analysis. ${ }^{41}$ Data analysis method was unclear in one of the included studies (table 3). ${ }^{34}$

One hundred and seventy-four trialists were interviewed or involved in focus groups in total: 62 general practitioners, 30 community physicians, 16 paediatricians, 11 surgeons, 11 recruiters, 10 clinicians, 10 nurses, five trainees, five investigators, four trial staff, four hospital doctors, two clinical studies officers, two research associates and two care coordinators. A broad range of settings were covered by the included studies, for example, primary and secondary care trials, drug trials and pragmatic surgery trials, trials in mental health and cancer, etc.

\section{Quality assessment}

Using the EPHPP quality assessment tool for quantitative studies, one study was characterised as strong, ${ }^{24}$ one as moderate ${ }^{25}$ with the remaining studies classified as weak. ${ }^{23}{ }^{26-30}$ Studies were shown to be particularly weak when reporting controlling for confounders and methods of data collection.

Overall, the qualitative studies assessed using the Critical Appraisal Skills Programme checklist were found to be of good quality. Methodology and consideration of ethical issues were the two main areas where reporting was unclear.

A summary of the quality of the included studies is shown in online appendixes 2 and 3.

\section{Results of review of quantitative studies}

Comparing types of recruiters

Two studies compared the use of different groups of clinicians recruiting to RCTs. Donovan $e t a l^{23}$ compared the effect of using nurses or urologic surgeons recruiting to a prostate cancer trial, using a RCT design. The trial showed no significant difference in recruitment rate between the two groups (RR 0.94, 95\% CI 0.76 to 1.17 ). The study also included an economic assessment that found nurses to be more cost-effective recruiters than surgeons.

Submacular Surgery Trials Research Group compared medical centres, in recruitment to three RCTs of recruitment at university-based and community-based 
Table 2 Summary of included quantitative studies

\begin{tabular}{|c|c|c|c|}
\hline & Study type & $\mathrm{RCT}$ recruiting to & Overview (country, aim) \\
\hline $\begin{array}{l}\text { Donovan et al } \\
(2003)^{23}\end{array}$ & $\mathrm{RCT}$ & $\begin{array}{l}\text { ProtecT Trial, prostate } \\
\text { cancer treatment }\end{array}$ & $\begin{array}{l}\text { UK } \\
\text { To investigate the comparative effectiveness } \\
\text { of nurses and surgeons in recruiting patients. }\end{array}$ \\
\hline $\begin{array}{l}\text { Monaghan et al } \\
(2007)^{24}\end{array}$ & $\mathrm{RCT}$ & $\begin{array}{l}\text { ADVANCE trial } \\
\text { (diabetes) }\end{array}$ & $\begin{array}{l}\text { Australia } \\
\text { Investigation of the effect of extra } \\
\text { communication from central trial } \\
\text { coordinators on recruitment. }\end{array}$ \\
\hline $\begin{array}{l}\text { Lienard et al } \\
(2006)^{25}\end{array}$ & $\mathrm{RCT}$ & $\begin{array}{l}\text { Adjuvant treatment } \\
\text { of breast cancer }\end{array}$ & $\begin{array}{l}\text { France } \\
\text { To assess the impact of on-site initiation } \\
\text { monitoring visits on patient recruitment. }\end{array}$ \\
\hline $\begin{array}{l}\text { Fletcher et al } \\
(2010)^{26}\end{array}$ & $\begin{array}{l}\text { Observational time } \\
\text { series }\end{array}$ & $\begin{array}{l}\text { Primary care-based } \\
\text { multicentre RCT, } \\
\text { stroke trial }\end{array}$ & $\begin{array}{l}\text { UK } \\
\text { To examine whether changes to the design } \\
\text { and conduct of a primary care-based RCT } \\
\text { were associated with changes in patient } \\
\text { recruitment. }\end{array}$ \\
\hline $\begin{array}{l}\text { Donovan et al } \\
(2002)^{27}\end{array}$ & $\begin{array}{l}\text { Observational time } \\
\text { series }\end{array}$ & $\begin{array}{l}\text { ProtecT trial-treatment } \\
\text { for prostate cancer }\end{array}$ & $\begin{array}{l}\text { UK } \\
\text { Feasibility study for main trial } \\
\text { Qualitative research used to address barriers } \\
\text { to recruitment and make changes to protocol. }\end{array}$ \\
\hline $\begin{array}{l}\text { Donovan et al } \\
(2009)^{28}\end{array}$ & $\begin{array}{l}\text { Before and after } \\
\text { study }\end{array}$ & $\begin{array}{l}\text { ProtecT trial-treatment } \\
\text { for prostate cancer }\end{array}$ & $\begin{array}{l}\text { UK } \\
\text { Main trial results } \\
\text { A complex intervention was designed using } \\
\text { qualitative methods to improve recruitment } \\
\text { (ie, regular training of recruiting staff, } \\
\text { centre reviews if centre not recruiting to } \\
\text { target, documents to provide advice and } \\
\text { personal feedback). }\end{array}$ \\
\hline $\begin{array}{l}\text { Kenyon et al } \\
(2005)^{29}\end{array}$ & $\begin{array}{l}\text { Before and after } \\
\text { study }\end{array}$ & $\begin{array}{l}\text { ORACLE trial-double-blind } \\
\text { RCT antibiotic treatment for } \\
\text { women in idiopathic preterm } \\
\text { labour }\end{array}$ & $\begin{array}{l}\text { UK } \\
\text { Trial was not recruiting successfully so } \\
\text { changes were made (introduction of lead } \\
\text { midwife responsible for recruitment with } \\
\text { protected time for research). }\end{array}$ \\
\hline $\begin{array}{l}\text { Submacular } \\
\text { Surgery Trials } \\
\text { Research Group } \\
(2004)^{30}\end{array}$ & $\begin{array}{l}\text { Case study (with } \\
\text { comparison group) }\end{array}$ & $\begin{array}{l}\text { SST-submacular surgery } \\
\text { trial }\end{array}$ & $\begin{array}{l}\text { USA } \\
\text { Comparison of university- and } \\
\text { community-based practices taking part in } \\
\text { three multicentre randomised trials. One } \\
\text { outcome measure was patient accrual. }\end{array}$ \\
\hline
\end{tabular}

intraocular surgery. ${ }^{30}$ This was a case study with comparison groups. The study found no significant difference between the settings (mean number of subjects recruited per centre: university $=38.1$, community $=37.3$, $t$ test $\mathrm{p}=0.93)$.

\section{Greater contact between trial coordinator and clinicians/trial sites}

Two studies examined the extent of contact on recruitment. Lienard et $a l^{25}$ used a RCT design to assess the impact of on-site monitoring visits on recruitment to a breast cancer RCT. On-site monitoring visits had multiple purposes: to ensure the protection of patients' rights, to verify the accuracy of reported data and to provide training to site personnel with regard to trial material and protocol. The study found that on-site monitoring visits had no significant effect on patient recruitment, reported as: centres recruiting at least one patient (control 34 of 67, intervention 35 of $68, \mathrm{p}>0.05$ ) or total numbers of patients recruited (control 271, intervention 302, $\mathrm{p}>0.05)$. No significant differences were found between groups in quality or quantity of reported data or patient follow-up time.

Monaghan et $a l^{24}$ (2007) used a RCT to evaluate the effect of extra communication from central trial coordinators on recruitment to a diabetes RCT. The intervention included frequent emails, personalised mail-outs of league tables describing recruitment performance relative to other centres, certificates acknowledging achievement of recruitment milestones and promotional materials related to the trial. The study found no significant effect of extra communication on median number of patients recruited (control 37.0, intervention $37.5, \mathrm{p}=0.68)$ or median time to half recruitment target (control 4.4 months, intervention 5.8 months, $\mathrm{p}=0.08)$. 
Table 3 Summary of included qualitative studies

\begin{tabular}{|c|c|c|c|}
\hline & Title & Study method and aims & Recruitment to RCT? \\
\hline $\begin{array}{l}\text { Hales et al } \\
(2001)^{31}\end{array}$ & $\begin{array}{l}\text { The conflicting roles of } \\
\text { clinicians versus investigators } \\
\text { in HIV randomised clinical } \\
\text { trials }\end{array}$ & $\begin{array}{l}\text { Semistructured interviews } \\
\text { One theme investigated } \\
\text { was recruitment. }\end{array}$ & $\begin{array}{l}\text { Yes } \\
\text { Clinical drug trial } \\
\text { Primary care and } \\
\text { secondary care }\end{array}$ \\
\hline $\begin{array}{l}\text { Caldwell et al } \\
(2002)^{32}\end{array}$ & $\begin{array}{l}\text { Paediatricians' attitudes } \\
\text { towards RCTs involving } \\
\text { children }\end{array}$ & $\begin{array}{l}\text { Focus groups } \\
\text { To examine doctors attitudes } \\
\text { towards children's } \\
\text { participation in RCTs and to } \\
\text { identify barriers to } \\
\text { participation. }\end{array}$ & $\begin{array}{l}\text { Yes } \\
\text { RCTs involving children } \\
\text { Secondary care (Teaching } \\
\text { hospital in Australia) }\end{array}$ \\
\hline $\begin{array}{l}\text { Jones et al } \\
(2003)^{33}\end{array}$ & $\begin{array}{l}\text { Building research capacity: } \\
\text { an exploratory model of GPs' } \\
\text { training needs and barriers } \\
\text { to research involvement }\end{array}$ & $\begin{array}{l}\text { Semistructured interviews } \\
\text { Investigation of GPs research } \\
\text { training needs, and barriers to } \\
\text { involvement in research. }\end{array}$ & Not specified \\
\hline $\begin{array}{l}\text { Mclntosh et al } \\
(2005)^{34}\end{array}$ & $\begin{array}{l}\text { Recruitment of physician } \\
\text { offices for an office-based } \\
\text { adolescent smoking cessation } \\
\text { study. }\end{array}$ & $\begin{array}{l}\text { Focus groups } \\
\text { To elicit perceptions of } \\
\text { facilitators and barriers to } \\
\text { initial engagement of } \\
\text { physician practices. }\end{array}$ & $\begin{array}{l}\text { Yes } \\
\text { Adolescent smoking } \\
\text { cessation study }\end{array}$ \\
\hline $\begin{array}{l}\text { Mason et al } \\
(2007)^{35}\end{array}$ & $\begin{array}{l}\text { GPs' experiences of primary } \\
\text { care mental health research: } \\
\text { a qualitative study of the } \\
\text { barriers to recruitment }\end{array}$ & $\begin{array}{l}\text { Semistructured interviews } \\
\text { To investigate the perceived } \\
\text { barriers among GPs to } \\
\text { introducing participation in } \\
\text { RCTs to patients with } \\
\text { depression. }\end{array}$ & $\begin{array}{l}\text { Yes } \\
\text { Primary care mental health } \\
\text { research }\end{array}$ \\
\hline $\begin{array}{l}\text { Ziebland et al } \\
(2007)^{36}\end{array}$ & $\begin{array}{l}\text { Does it matter if clinicians } \\
\text { recruiting for a trial do not } \\
\text { understand what the trial is } \\
\text { really about? Qualitative study } \\
\text { of surgeons' experiences of } \\
\text { participation in a pragmatic } \\
\text { multicentre RCT }\end{array}$ & $\begin{array}{l}\text { In-depth interviews } \\
\text { To explore physicians } \\
\text { understanding of the trial } \\
\text { purpose and how this } \\
\text { understanding had influenced } \\
\text { their recruitment. }\end{array}$ & $\begin{array}{l}\text { Yes } \\
\text { Multicentre pragmatic RCT } \\
\text { Spinal surgery }\end{array}$ \\
\hline $\begin{array}{l}\text { Bill-Axelson et al } \\
(2008)^{37}\end{array}$ & $\begin{array}{l}\text { Experiences of randomisation } \\
\text { interviews with patients and } \\
\text { clinicians in the SPG-IV trial }\end{array}$ & $\begin{array}{l}\text { Semistructured interviews } \\
\text { Investigation of patients' and } \\
\text { clinicians' experiences of } \\
\text { randomisation with the aim of } \\
\text { facilitating future trial } \\
\text { participation. }\end{array}$ & $\begin{array}{l}\text { Yes } \\
\text { Prostate cancer RCT }\end{array}$ \\
\hline $\begin{array}{l}\text { Potter et al } \\
(2009)^{38}\end{array}$ & $\begin{array}{l}\text { A qualitative study exploring } \\
\text { practice nurses' experience of } \\
\text { participating in a primary } \\
\text { care-based RCT }\end{array}$ & $\begin{array}{l}\text { Semistructured interviews } \\
\text { To explore the views of } \\
\text { practice nurses' recruiting into } \\
\text { a primary care-based RCT } \\
\text { and to investigate factors that } \\
\text { influence the success of trial } \\
\text { recruitment. }\end{array}$ & $\begin{array}{l}\text { Yes. } \\
\text { Primary care-based RCT } \\
\text { to promote adherence to } \\
\text { treatment of people with } \\
\text { type } 2 \text { diabetes. }\end{array}$ \\
\hline $\begin{array}{l}\text { Howard et al } \\
(2009)^{39}\end{array}$ & $\begin{array}{l}\text { Why is recruitment to trials } \\
\text { difficult? An investigation into } \\
\text { recruitment difficulties in an } \\
\text { RCT of supported employment } \\
\text { in patients with } \\
\text { severe mental illness }\end{array}$ & $\begin{array}{l}\text { Interviews } \\
\text { To evaluate reasons for } \\
\text { under-recruitment in an RCT. } \\
\text { Trial staff and recruiting } \\
\text { physicians were interviewed. }\end{array}$ & $\begin{array}{l}\text { Yes. } \\
\text { RCT of supported } \\
\text { employment in patients with } \\
\text { severe mental illness. }\end{array}$ \\
\hline $\begin{array}{l}\text { Patterson et al } \\
(2010)^{40}\end{array}$ & $\begin{array}{l}\text { The great divide: a qualitative } \\
\text { investigation of factors } \\
\text { influencing researcher access } \\
\text { to potential RCT participants } \\
\text { in mental health settings }\end{array}$ & $\begin{array}{l}\text { Interviews } \\
\text { Using Grounded Theory } \\
\text { process evaluation of a } \\
\text { multicentre trial to investigate } \\
\text { factors influencing referral to } \\
\text { potential RCTs in mental } \\
\text { health settings. }\end{array}$ & $\begin{array}{l}\text { Yes } \\
\text { Potential RCTs in mental } \\
\text { health setting }\end{array}$ \\
\hline
\end{tabular}




\begin{tabular}{|c|c|c|c|}
\hline & Title & Study method and aims & Recruitment to RCT? \\
\hline $\begin{array}{l}\text { Paramasivan } \\
\text { et al }(2011)^{41}\end{array}$ & $\begin{array}{l}\text { Key issues in recruitment to } \\
\text { RCTs with very different } \\
\text { interventions: a qualitative } \\
\text { investigation of recruitment } \\
\text { to the SPARE trial }\end{array}$ & $\begin{array}{l}\text { Interviews; content analysis of } \\
\text { RCT documents; conversation } \\
\text { analysis of recruitment } \\
\text { appointments } \\
\text { To explore reasons for low } \\
\text { recruitment and attempt to } \\
\text { improve recruitment rate by } \\
\text { implementing changes suggested } \\
\text { by qualitative findings. }\end{array}$ & $\begin{array}{l}\text { Yes } \\
\text { Bladder cancer treatment } \\
\text { trial-feasibility study }\end{array}$ \\
\hline
\end{tabular}

\section{Use of qualitative research embedded in host RCT}

Two studies investigated the use of qualitative methods embedded in a host trial. In both studies, qualitative methods (in-depth interviews, audiotape recordings of recruitment appointments, study of trial documents) and analysis (content, thematic and conversation analysis) were used to assess aspects of the trials that were amenable to improvement; followed by the design and implementation of interventions to improve the recruitment activity of clinicians. Donovan et al (2002) reports the results of a feasibility study before the main trial (Donovan et al 2009). ${ }^{27} 28$

Donovan et $a l^{27}$ (2002) reported the results of an observational time series study investigating recruitment to a prostate cancer RCT. Qualitative methods were used to elicit strategies, which had the potential to improve recruitment. Strategies identified by qualitative methods included presentations of the study design and the implementation of a training programme delivered to clinicians. The intervention improved the proportion of eligible patients consenting to randomisation (after 10 months, RR $1.36,95 \%$ CI 1.01 to 1.85 ), while there was no significant change in the proportion of randomised patients accepting allocation (after 10 months, RR $0.90,95 \%$ CI 0.70 to 1.15 ).

Donovan et al $(2009)^{28}$ reported the results of the main trial. Qualitative methods allowed a complex intervention to be developed which included regular training for all staff involved in recruitment and initiation for new staff, centre reviews for underperformers, documents providing tips and advice and personalised individual feedback to recruiters as required. The study reports the results of audits of two centres before and after the intervention (12 and 24 months post-intervention). The results of the two centres are not pooled in this review as interventions were tailored to each centre using qualitative research; therefore, the intervention that the two centres received was different. The first centre showed a significant improvement in the proportion of eligible patients recruited at 12 months (RR 1.87, 95\% CI 1.15 to 3.04) and 24 months (RR 1.79, 95\% CI 1.07 to 2.99 ) post-intervention, and no significant change in the proportion of randomised patients accepting allocation (12 months, RR 1.22, 95\% CI 0.62 to 2.39 ; 24 months, RR $1.43,95 \%$ CI 0.75 to 2.71 ). The second centre also showed a significant improvement in the proportion of eligible patients recruited at 12 months (RR 1.55, 95\% CI 1.11 to 2.16 ) and no significant change at 24 months (RR 1.36, 95\% CI 0.92 to 2.02) post-intervention. No significant change in the proportion of randomised patients accepting allocation was found at 12 months (RR 1.33, 95\% CI 0.96 to 1.85 ) and a slight increase in those accepting allocation at 24 months (RR $1.44,95 \%$ CI 1.05 to 1.99 ).

\section{Complex intervention}

Fletcher $e t a l^{26}$ used an observational time series study design to examine whether changes in the conduct of a stroke RCT were associated with changes in recruitment. Over the recruitment period, changes included procedural changes to reduce clinician workload and time to recruitment, enrolment of more sites and changes to the approach to recruitment and retention of practices. Recruitment rates per 1000 eligible population were calculated, and a moving $F$ statistic was used to assess changes over time. There was a statistically significant increase in recruitment in the last 6 months of the trial associated with efforts to reduce clinician workload.

\section{Extra training and protected research time}

Kenyon et $a l^{29}$ used a before and after study design to measure the effect of increased training, and paying for protected research time for midwives recruiting to a large perinatal multicentre RCT. The intervention involved the employment of lead local midwives to work for 3 hours per week on the trial. The midwives were provided with intensive training, 6 monthly updates and regular contact visits. Recruitment in all the maternity units improved by an average of $69 \%$ (range $-89 \%$ to $200 \%$ ) when comparing the 6 months prior to the intervention with the 6 months immediately after the intervention.

\section{Results of review of qualitative studies}

Findings relating to clinicians' involvement in, and recruiting to RCTs, were extracted for each of the 11 
included studies. A line-by-line content analysis isolated a total of 73 findings, which were consolidated into eight abstracted themes by combining like statements and eliminating redundant statements. There is some overlap between abstracted findings. The abstracted themes are described below.

\section{Understanding of research (in general; RCTs; in light of specific trials)}

RCTs are understood by clinicians to be a valuable tool in healthcare (ie, description of RCT as gold standard; RCTs provide the best available evidence); however, it is suggested that some clinicians are exposed to too much research, leading to a feeling of being overwhelmed with requests for research participation.

It is reported that there is a poor understanding among clinicians of RCT methods and concepts (ie, equipoise, randomisation, allocation, eligibility criteria, informed consent), along with the opinion that RCTs can be too complex.

There is some discussion regarding the funding of research, for example, questioning whether RCTs are the best way to spend money, particularly given the current economic climate; is there enough money available for research.

It is seen to be the responsibility of the whole community (researchers, clinicians and patients) to take part in research. However, some clinicians are suspicious of the motives of researchers, and others have no interest in research whatsoever-leading to resistance to research participation (obstructive/difficult to engage).

\section{Communication (clinician to patient; clinician to trial coordinator)}

Clinicians report a difficulty in communicating the aims and concepts of RCTs to patients. The choice of language used is perceived as very important. Communicating research to patients is described as a sales pitch. Language used to describe RCT design is a concern, particularly allocation and randomisation, which has been likened to describing a lottery, with 'winners and losers'.

Clinicians report that they are able to communicate with certain patients and patient groups about RCTs better than others. Social class of patients is discussed, with clinicians finding communication with 'people like themselves' easier.

Poor communication of research by trial coordinators can lead to suspicion of their motives. There is often a perceived divergence between clinical and research goals. Clinicians feel that they should be seen as 'partners in research', with greater involvement in design leading to improved recruitment.

\section{Perceived patient barriers}

Barriers to recruitment are often seen by clinicians to be more related to the patients, and therefore out of their control. Perceived patient barriers include poor community awareness and understanding of RCTs, low motivation to take part in research, lack of interest, fear and mistrust of being treated as guinea pigs and fear of negative effects of taking part.

\section{Patient-clinician relationship}

Clinicians acting as recruiters are particularly concerned with the conflicting roles that taking part in research activities imposed.

Recruiting clinicians may act as gatekeepers, only suggesting research to those patients that they deem suitable for research (ie, not approaching all patients who meet eligibility criteria for a study). This can be perceived to be paternalistic as clinicians make decisions on the patients' behalf, believing that they know what is best, without consulting the patients.

Clinicians feel responsible for the patients they put forward for research, particularly as they believe they can influence patients' decision making. Also clinicians put patient needs above those of researchers; patient well-being is seen as paramount.

Concern that trust may be affected by asking patients to take part in research is mentioned, as well as the concern for some clinicians that they risk feelings of ineptitude or rejection if they invite patients to take part in RCTs and they refuse.

\section{Effect on patients (harms and benefits)}

Clinicians often describe possible patient benefit as motivation for participation in RCTs, and equally concerns are expressed about possible harms. Some clinicians have difficulty reconciling potentially putting individual patients at risk for possible population gain. Clinicians want to avoid being seen to pressurise patients to take part in RCTs.

The stage of patient illness is a concern, as it is suggested that asking terminally ill patients or patients with poor prognosis to take part in an RCT with a placebo can be emotionally detrimental for some patients. Also, side effects of treatments used in RCTs are seen as possible negatives for patients. It is important to note that these are what the clinicians perceive their patients to be thinking, and the patients themselves may not share these views.

Inviting patients to take part in research can have the effect of raising patient awareness of disease, which can be interpreted in both a positive and negative light (ie, more awareness may lead to increased participation in research but also more health seeking behaviour, stretching current resources).

Research can be thought to be inequitable by clinicians, with some special patient groups seen as receiving more attention than others.

\section{Effects on clinical practice}

A positive aspect of taking part in RCTs is the beneficial influence it can have on clinical practice. Being a research active practice enhances services offered by practices, encouraging confidence and loyalty from patients. It is also thought that the discipline needed to 
adhere to some trial protocols has beneficial effects on clinical practice.

Advancements in clinical practice are dependent on carrying out good quality clinical trials. Taking part in RCTs can improve treatment strategies used in everyday practice, conferring benefits to patients outside the RCT in the medium and long term.

Negatives include the possible disruption caused to normal practice brought about by the extra work involved in assessing patients for eligibility and approaching those who are eligible for participation (ie, describing RCT, obtaining informed consent, etc). The extra time associated with recruiting to RCTs in addition to normal duties is often stated as a major barrier to involvement. In the climate of trying to achieve service targets within tight budgets, carrying out extra work to recruit patients to trials may not be seen as a priority.

It is felt by some clinicians that although they are crucial to the successful running of trials by recruiting subjects, they often do not receive the acknowledgment/ rewards they feel they deserve. Being asked to recruit for RCTs is seen to be intrusive by some clinicians.

\section{Individual benefits for clinicians}

Motivation for involvement in research can be seen to move beyond altruism. Taking part and recruiting patients to RCTs is seen by many to have personal benefits for clinicians. Involvement with colleagues from different fields is seen to be important personally, as well as professionally.

Participation in RCTs is seen by some as crucial for career development and professional recognition.

\section{Methods associated with successful recruitment}

Community awareness of RCTs and research in general is linked to good recruitment. Promotion efforts should be tried to improve awareness, which should have the effect of increasing the number of patients willing to take part in RCTs. Endorsements of research by the patients' own general practitioner or practice can improve recruitment.

The research question addressed by an RCT is of vital importance to clinicians. The question should be both interesting and relevant to practice. Initial contact with clinicians about involvement in a trial should be brief but informative. Trial methods should be easy to understand and then to communicate to patients. Inviting recruiters to take part in the design of RCTs could improve recruitment.

The funding of protected research time is an intervention that could improve recruitment performance. This would allow clinicians more time to discuss the trial with patients. More time would also allow clinicians to tailor their approach to each individual, an approach that is desirable for some clinicians. If protected research time is not a possibility, then minimisation of workload related to recruitment is the key.

Financial incentives are important for many, with criticism when reimbursement for time is not offered.
Clinicians should be reimbursed for time spent on recruitment rather than placing a bounty on patients' heads. Conversely some argue that financial incentives are unethical, and others that being paid would not significantly affect recruitment efforts. It was also noted that all staff should be rewarded for participation in research, not just clinicians.

Organisationally, being part of a research active practice is linked with good recruitment to RCTs. Having a research mentor or a trial coordinator or being involved in a research network are also factors in successful recruitment. Competition with other recruiters is a constructive way to maximise recruitment.

Appropriate training about research methods and recruitment methods is regarded as the key to success by many. Training should focus on addressing many common misconceptions about RCTs, particularly equipoise and informed consent.

\section{Qualitative frequency effect size (metasummary)}

By dividing the number of studies containing each theme/abstracted finding by the total number of studies, a frequency effect size was calculated. Table 4 shows the findings with frequency effect sizes $>20 \%$, as proposed by Sandelowski and Barroso. ${ }^{22} \mathrm{~A}$ full list of findings and frequency effect sizes is given in online appendix 4 .

Difficulty communicating trial methods (randomisation, equipoise, etc) was the most common subtheme (64\%) and was linked to a poor understanding of research methods by clinicians, and research in general by the public (55\%). Ease of understanding and carrying out RCT methods was also commonly described as associated with successfully recruiting trials (45\%).

Clinicians found it difficult reconciling the roles of clinician and recruiter (36\%). Clinicians were often described to only put forward patients who they deemed appropriate (gatekeeping) (27\%), which links to paternalism $(27 \%)$ and prioritising patient well-being $(45 \%)$.

The positive and negative aspects of taking part in RCTs were frequently mentioned, with a balance between possible negative $(36 \%)$ and positive effects on patients $(27 \%)$ and the effect on clinical practice $(45 \%)$.

The most frequently found abstracted finding was methods associated with successful recruitment to RCTs, with four subthemes with a frequency effect $>20 \%$. It was thought that the research question should be interesting and relevant to practice (45\%). Financial incentives were seen by most as important for participation (27\%). Training relevant to running trials should improve recruitment by targeting poor understanding of RCT methodology, as well as teaching recruitment methods $(45 \%)$.

\section{DISCUSSION}

The aim of this review was to identify, and synthesise, evidence of the effectiveness of interventions aimed at improving the recruitment activity of clinicians in RCTs, 
Table 4 Summary of qualitative findings with frequency effect size $>20 \%$

\begin{tabular}{|c|c|c|c|}
\hline Abstracted finding & Subtheme & $\begin{array}{l}\text { Studies in which } \\
\text { subtheme is present }\end{array}$ & $\begin{array}{l}\text { Frequency } \\
\text { effect size (\%) }\end{array}$ \\
\hline \multirow[t]{2}{*}{ Understanding of research } & RCTs provide the best evidence. & 313536 & 27 \\
\hline & Poor understanding of research & $32333639-41$ & 55 \\
\hline Communication & Difficulty communicating trial methods & $3132353739-41$ & 64 \\
\hline \multirow[t]{5}{*}{ Patient-clinician relationship } & $\begin{array}{l}\text { Conflicting roles of being a recruiting } \\
\text { physician }\end{array}$ & 31353940 & 36 \\
\hline & Clinicians acting as gatekeepers & $38-40$ & 27 \\
\hline & Paternalism & 353839 & 27 \\
\hline & $\begin{array}{l}\text { Clinician influence on patient decision } \\
\text { making }\end{array}$ & 32353739 & 36 \\
\hline & Patient well-being a priority & 3132353739 & 45 \\
\hline \multirow[t]{2}{*}{ Effect on patients } & Possible benefits of taking part in RCTs & 31323438 & 36 \\
\hline & Possible harms of taking part in RCTs & 313639 & 27 \\
\hline Effect on clinical practice & Positive effect of being involved in RCTs & 3132343538 & 45 \\
\hline Individual benefit for clinician & Career development & 323841 & 27 \\
\hline Methods associated with & Importance of research question & $313235-37$ & 45 \\
\hline \multirow[t]{3}{*}{ successful recruitment } & $\begin{array}{l}\text { Trial methods easy to understand, } \\
\text { communicate and carry out }\end{array}$ & 3234373841 & 45 \\
\hline & Financial incentives & 313334 & 27 \\
\hline & Appropriate training & $32-3438$ & 36 \\
\hline
\end{tabular}

and evidence of their attitudes towards recruitment to RCTs.

\section{Methodological challenges}

As the volume of evidence was perceived to be small, an aim of the review was to include as much evidence as possible, regardless of method, several methodological issues had to be dealt with. Many systematic reviews of interventions exclude studies that do not use RCTs. While good quality RCTs of interventions would provide the best evidence, the nature of this research question lends itself to retrospective descriptive studies. This may be due to the logistical, ethical and scientific obstacles of performing randomised trials of recruitment nested within host RCTs. ${ }^{42}$ Challenges for host trials include increasing complexity and management burden, compatibility between host and nested study and the impact of the nested study on host trial design. Challenges for nested studies include investigators' concerns that host study investigators might have strong preferences, limiting the nested study investigators control over their research; and concerns about sample size which might limit statistical power. 'Evidential nihilism', where narrow inclusion criteria are set regarding trial design would have led to an emptier review, which would not help further our understanding of the problem as much. ${ }^{43}$ Qualitative studies were included in this review as it is important not just to understand what works but also to have an understanding of why. It is hoped that a better understanding of clinicians' attitudes towards recruitment to RCTs may inform the development of interventions aimed to improve the support and training given to those involved in RCTs.
The search was broad and included no methodological filters, but still returned a large number of results. There is often a trade-off between sensitivity and specificity when performing a search for a systematic review, and in this case, it was decided to err on the side of over inclusion, so a sensitive search was designed.

The review of quantitative studies found limited highquality evidence of interventions aimed at improving clinician activity and shows the importance of building the evidence base to allow those running RCTs to have access to a range of proven strategies to maximise recruitment. Quality of the included qualitative studies was found to be good; however, there was a tendency for the included studies to focus on the barriers to recruitment from the perspective of poorly recruiting trials. Little evidence was found of studies that aimed to assess how and why those clinicians who recruited well did so. It could be argued that facilitators are more illuminating, as barriers can often be seen as excuses, that is, if the barrier was removed would the clinicians recruit more successfully?

\section{What interventions work?}

Evidence-based interventions are necessary for RCTs to recruit successfully; however, there is currently limited evidence, and interventions are being used that have no evidential grounding. For example, a study of seven primary care-based RCTs found that only $37 \%$ of interventions to promote recruitment were judged to be evidence based. ${ }^{7}$ Further to this, Graffy et $a l^{42}$ stated that currently, where nested studies of recruitment methods are conducted on the initiative of individual investigators, there is no systematic method of choosing the 
intervention. The authors go on to suggest the creation of a portfolio of interventions that could be made available to investigators for inclusion within an individual trial or multiple trials.

This lack of evidence-based interventions is particularly salient given that 'common sense', interventions that could be assumed to have a positive effect on recruitment often had little or no effect. The most successful intervention identified by this review was in the two trials that used embedded qualitative research to design interventions to improve recruitment. The qualitative research investigated recruitment appointments, study documents and interviewed clinicians to understand what aspects were amenable to change in order to improve recruitment. In both studies, the intervention increased recruitment, that is, the proportion of eligible subjects who consented to be randomised in the study. Rather than discuss the strategies used to improve recruitment, the most important factor in studies employing embedded qualitative research is the way that the intervention is developed. The use of qualitative methods allowed tailored interventions to be made that attempted to address problems with recruitment that were experienced by the clinicians and trial subjects (ie, use of interviews, monitoring of recruitment interviews), as well as problems identified by the trial coordinators. This method is adaptive and allows for continuous monitoring and improvement. Although the interventions themselves may not be generalisable, the qualitative methods used to create the interventions could be transferred to other settings, potentially having a positive effect on recruitment. Another positive feature of this approach was that improvements were maintained over time. Following intervention at two centres, recruitment was shown to remain significantly higher for at least 24 months.

One possible barrier to the use of this approach may be the extra time, money and personnel needed to carry out the qualitative research. However, the use of qualitative methods in pilot or feasibility trials prior to a full study would provide a cost-effective means of defining suitable interventions that could be fully incorporated into subsequent trials. If these interventions then proved successful in aiding recruitment, the extra efforts and costs involved in the preparatory phases would be offset by the greater potential for a successful full trial that would result, providing greater returns to funders and increasing the scientific validity of the trial overall.

\section{Clinicians' attitudes to recruitment to RCTs}

Setting aside the debate regarding the utility of metasummary frequency effect sizes, in this review, there are three key areas highlighted by the calculation of qualitative effect sizes that may be the best target for improvement in future trials: understanding of RCTs and health research in general (both by the general public and by clinicians), communication of trial methods (both trial coordinators to clinicians and clinicians to patients) and reduction of the workload associated with recruitment.

It should not be assumed by trial coordinators that recruiters have a full understanding of RCT and recruitment methods. Clinicians' understanding of research in general and RCTs in particular could be improved using training specific to the RCT they are involved in as well as education relating to common misconceptions about RCTs.

Some of the themes identified could be used to emphasise the individual benefits to both trial subjects and clinicians, and the positive effect taking part in research can have on clinical practice. ${ }^{44}$ For example, a study of centres involved in a multicentre breast cancer treatment trial found that both patients and clinicians benefited from participation in the RCT, due to optimised decision making with regard to therapy and patient care. ${ }^{45}$ An overall positive effect on the quality of medical care was seen across the centres. As clinicians prioritise patient well-being, emphasising the potential patient benefits to them could help remove a barrier to recruitment.

It is clear that reported barriers may often be excuses for why clinicians have not recruited well. Patterson et $a l_{,}^{40}$ for example, found that concerns about taking part in RCTs related to ethics and research approvals, but even when these issues were addressed clinicians remained less than enthusiastic and instead shifted the blame to administrative and clinical duties. Removal of the perceived barrier will not necessarily lead to an improvement in recruitment. This again highlights that more investigation is required to illuminate what facilitates trials that easily meet their recruitment targets.

Reducing clinicians' workload associated with recruiting to RCTs was often mentioned. This could be achieved by providing extra staff support, simplification of recruitment protocols or providing protected research time. However, it remains to be seen whether clinicians saying they do not have enough time is more commonly a barrier or an excuse.

Clinicians place an emphasis on patient well-being, and some may feel the need to protect their patients from the risk of taking part in a RCT. A commonly held belief among clinicians is that patients who take part in RCTs face risks that they would not otherwise face if they received their healthcare in the usual manner. However, a systematic review found that the outcomes of patients taking part in RCTs do not differ from those of patients receiving similar treatments who do not participate. ${ }^{45}$

Engaging clinicians in RCTs is a crucial step in the recruitment process. It is apparent that clinicians are aware of the impact they have on their patients' decision making regarding involvement in trials, and it has been shown that personal endorsement of trials by clinicians can have a positive effect on recruitment. If clinicians are fully engaged and understand the benefits, to both themselves and patients, of participating in RCTs, recruitment could improve significantly. 


\section{CONCLUSIONS}

Few high-quality trials were identified that tested interventions to improve clinicians' recruitment activity in RCTs. The most promising intervention was the use of qualitative methods to identify and overcome barriers to clinician recruitment activity. It is clear that the barriers to nested trials of recruitment interventions in host RCTs must be overcome in future in order to add to the evidence base.

The metasummary of qualitative findings identified understanding and communicating RCT methods (clinician to patient and trial coordinator to clinician) as a key target for future interventions to improve recruitment. Reinforcement of the potential benefits, both for clinicians and for their patients, could also be a successful factor in improving recruitment. A bias was found towards investigating barriers to recruitment, so future work should also encompass a focus on successfully recruiting trials.

Few reviews attempt to synthesise qualitative evidence using the methods demonstrated here, and it is hoped that this review demonstrates the utility of methods for synthesising diverse evidence. Hopefully by bringing together a review of qualitative and quantitative studies, we have created a report that is more informative than carrying out two reviews in isolation.

It is hoped that this work will inform the development of future studies investigating clinicians' attitudes to recruitment, as well as the design of possible future recruitment interventions to be tested using a robust trial design.

Funding This work was carried out using funding from an NIHR Methods Fellowship awarded to BF.

\section{Competing interests None.}

Contributors BF made substantial contributions to the design of the study, acquisition and interpretation of data, synthesis of qualitative evidence, and wrote the final draft of the article. AG was involved in acquisition, analysis and interpretation of data. SW contributed substantially to the conception and design of the study and was responsible for obtaining funding for the study. DM contributed substantially to the design of the study, particularly search strategy, data analysis and quality assessment of quantitative papers. SD contributed substantially to the design of the study, advised on qualitative quality assessment, data extraction and metasummary. All authors contributed to drafting the manuscript and revising it critically for intellectual content, and all authors have seen and approved the final version of the manuscript.

Provenance and peer review Not commissioned; externally peer reviewed.

Data sharing statement Data deposited in the Dryad repository: doi:10.5061/dryad.4dg4v0c8.

\section{REFERENCES}

1. Collins R, Doll R, Peti R. Ethics in clinical trials. In: Williams CJ, ed, Introducing New Treatments for Cancer: Practical, Ethical and Legal Problems. Chichester: John Wiley, 1992:49-56.

2. Treweek S, Mitchell E, Pitkethly M. Strategies to improve recruitment to randomised controlled trials. Cochrane Database Syst Rev 2010; (4):MR000013.

3. Watson JM, Torgerson DJ. Increasing recruitment to randomised controlled trials: a review of randomised controlled trials. BMC Med Res Methodol 2006;6:34.
4. Charleson ME, Horwitz RI. Applying results of randomised controlled trials to clinical practice: impact of losses before randomisation. $\mathrm{Br}$ Med J (Clin Res Ed) 1984;289:1281-4.

5. Easterbrook PJ, Matthews DR. Fate of research studies. J R Soc Med 1992;85:71-6.

6. Wilson S, Delaney BC, Roalfe A. Randomised controlled trials in primary care: a case study. BMJ 2000;321:24-7.

7. Foy R, Parry J, Duggan A. How evidence based are recruitment strategies to randomised controlled trials in primary care? Experience from seven studies. Fam Pract 2003;20:83-92.

8. McDonald AM, Knight RC, Campbell MK. What influences recruitment to randomised controlled trials? A review of trials funded by two UK funding agencies. Trials 2006;7:9.

9. Bower P, Wilson S, Mathers N. Short report: how often do UK primary care trials face recruitment delays? Fam Pract 2007;24:601-3.

10. Raftery J, Bryant J, Powel J. Payment to healthcare professionals for patient recruitment to trials: systematic review and qualitative study. Health Technol Assess 2008;12:1-128, iii.

11. Toerien M, Brookes ST, Metcalfe C. A review of reporting of participant recruitment and retention in RCTs in six major journals. Trials 2009;10:52

12. Rendell JM, Merritt RK, Geddes J. Incentives and disincentives to participation by clinicians in randomised controlled trials. Cochrane Database Syst Rev 2007;(2):MR000021.

13. Rangerink KO, Opmeer BC, Logtenberg SL. IMproving PArticipation of patients in Clinical Trials-rationale and design of IMPACT. BMC Med Res Methodol 2010;10:85.

14. Mapstone J, Elbourne D, Roberts IG. Strategies to improve recruitment to research studies. Cochrane Database Syst Rev 2007; (2):MR000013.

15. Campbell MK, Snowdon C, Francis D. Recruitment to randomised controlled trials: strategies for trial enrolment and participation study The STEPS study. Health Technol Assess 2007;11:iii, ix-105.

16. Prescott RJ, Counsell CE, Gillespie WJ. Factors that limit the quality and progress of randomised controlled trials. Health Technol Assess 1999;20:1-143.

17. Effective Public Health Practice Project. Quality Assessment Tool for Quantitative Studies. http://www.ephpp.ca/PDF/Quality\% 20Assessment\%20Tool 2010_2.pdf

18. Deeks JJ, Dinnes J, D'Amico R. Evaluating non-randomised intervention studies. Health Technol Assess 2003;7:iii-x, 1-173.

19. Critical Appraisal Skills Programme. 10 Questions to Help You Make Sense of Qualitative Research. http://www.sph.nhs.uk/sph-files/caspappraisal-tools/Qualitative\%20Appraisal\%20Tool.pdf

20. Thomas J, Harden A. Methods for the thematic synthesis of qualitative research in systematic reviews. BMC Med Res Methodol 2008;8:45.

21. Onwuegbuzie AJ. Effect sizes in qualitative research a prolegomenon. Quality and Quantity 2003;37:393-409.

22. Sandelowski M, Barroso J. Handbook for Synthesizing Qualitative Research. New York: Springer, 2007.

23. Donovan JL, Peters TJ, Noble S. Who can best recruit to randomized trials? Randomized trial comparing surgeons and nurses recruiting patients to a trial of treatments for localized prostate cancer (the ProtecT study). J Clin Epidemiol 2003;56:605-9.

24. Monaghan $\mathrm{H}$, Richens $\mathrm{A}$, Colman S. A randomised trial of the effects of an additional communication strategy on recruitment into a largescale, multi-centre trial. Contemp Clin Trials 2007;28:1-5.

25. Lienard JL, Quinaux E, Fabre-Guillevin E. Impact of on-site initiation visits on patient recruitment and data quality in a randomized trial of adjuvant chemotherapy for breast cancer. Clin Trials 2006;3:486-92.

26. Fletcher K, Mant J, Roalfe A. Impact of study design on recruitment of patients to a primary care trial: an observational time series analysis of the Birmingham Atrial Fibrillation Treatment of the Aged (BAFTA) study. Fam Pract 2010;27:691-7.

27. Donovan J, Mills N, Smith M. Improving design and conduct of randomised trials by embedding them in qualitative research: ProtecT (prostate testing for cancer and treatment) study. BMJ 2002;325:766-70.

28. Donovan JL, Lane JA, Peters TJ. Development of a complex intervention improved randomization and informed consent in a randomized controlled trial. J Clin Epidemiol 2009;62:29-36.

29. Kenyon S, Rhodes A, Taylor D. A recipe for successful recruitment to a randomised controlled trial. MDIRS Midwifery Digest 2005;15:16-19.

30. Submacular Surgery Trials Research Group (SSTRG). Clinical trial performance of community vs university based practices in the submacular surgery trials (SST). Arch Opthamol 2004;122:857-63.

31. Hales G, Beveridge A, Smith D. The conflicting roles of clinicians versus investigators in HIV randomised clinical trials. Cult Health Sex 2001;3:67-9. 
32. Caldwell PH, Butow PN, Craig JC. Pediatricians' attitudes toward randomized controlled trials involving children. $J$ Pediatr 2002;141:798-803.

33. Jones A, Burgess TA, Farmer EA. An exploratory model of GPs' training needs and barriers to research involvement. Aust Fam Physician 2003:32:955-8.

34. McIntosh S, Ossip-Klein DJ, Hazel-Fernandez L. Recruitment of physician offices for an office-based adolescent smoking cessation study. Nicotine Tob Res 2005;3:405-12.

35. Mason VL, Shaw A, Wiles NJ. GPs' experiences of primary care mental health research: a qualitative study of the barriers to recruitment. Fam Pract 2007;24:518-25.

36. Ziebland S, Featherstone K, Snowden C. Does it matter if clinicians recruiting for a trial don't understand what the trial is really about? Qualitative study of surgeons' experiences of participation in a pragmatic multi-centre RCT. Trials 2007;8:4.

37. Bill-Axelson A, Christensson A, Carlsson M. Experiences of randomisation: interviews with patients and clinicians in the SPCG-IV trial. Scand J Urol Nephrol 2008;42:358-63.

38. Potter R, Dale J, Caramlau I. A qualitative study exploring practice nurses' experience of participating in a primary care-based randomised controlled trial. J Res Nurs 2009;14:439-47.

39. Howard L, de Salis I, Tomlin Z. Why is recruitment to trials difficult? An investigation into recruitment difficulties in an RCT of supported employment in patients with severe mental illness. Contemporary Clin Trials 2009;30:40-6.

40. Patterson S, Kramo K, Soteriou T. The great divide: a qualitative investigation of factors influencing researcher access to potential randomised controlled trial participants in mental health settings. $J$ Ment Health 2010:19:532-41.

41. Paramasivan S, Huddart R, Hall E. Key issues in recruitment to randomised controlled trials with very different interventions: a qualitative investigation of recruitment to the SPARE trial. Trials 2011;12:78.

42. Graffy J, Bower P, Ward E. Trials within trials? Researcher, funder and ethical perspectives on the practicality and acceptability of nesting trials of recruitment methods in existing primary care trials. BMC Med Res Methodol 2010;10:38.

43. Petticrew M. Systematic reviews in public health: old chestnuts and new challenges. Bull World Health Organ 2009;87:163.

44. Janni W, Sommer H, Rack B. Study participation improves treatment strategies and individual patient care in participating centers. Anticancer Res 2006;26:3661-8.

45. Vist GE, Bryant D, Somerville L. Outcomes of patients who participate in randomized controlled trials compared to similar patients receiving similar interventions who do not

participate (Review). Cochrane Database Syst Rev 2008;(3): MR000009. 